\title{
Partial mitigation of oxidised phospholipid-mediated mitochondrial dysfunction in neuronal cells by oxocarotenoids
}

Opeyemi S Ademowo ${ }^{1}$, Irundika HK Dias ${ }^{1 *}$, Lorena Diaz-Sanchez ${ }^{1}$, Lissette Sanchez-Aranguren ${ }^{1}$ Wilhelm Stahl ${ }^{2}$, Helen R Griffiths ${ }^{1,3 *}$

1. Aston Medical Research Institute, Aston Medical School, Aston University, Birmingham, B4 7ET, $U K$

2. Institute of Biochemistry and Molecular Biology 1, Faculty of Medicine, Heinrich-Heine-University Dusseldorf, D-40001Dusseldorf, Germany

3. Faculty of Health and Medical Sciences, University of Surrey, Stag Hill, Guildford, GU2 7XH, UK *Corresponding authors email; h.r.griffiths@surrey.ac.uk and diashki1@aston.ac.uk Tel:+44 (0)1483 689586

Running title: Carotenoids and mitochondrial function 


\section{Abstract}

Mitochondria are important (patho)physiological sources of reactive oxygen species (ROS) that mediate mitochondrial dysfunction and phospholipid oxidation; an increase in mitochondrial content of oxidised phospholipid (OxPL) associates with cell death.

Previously we showed that the circulating OxPL 1-palmitoyl-2-(5'-oxo-valeroyl)-sn-glycero-3phosphocholine (POVPC) increases in patients with Alzheimer's disease (AD), and associates with lower plasma antioxidant oxocarotenoids, zeaxanthin and lutein. Since oxocarotenoids are metabolised in mitochondria, we propose that during $\mathrm{AD}$, lower concentrations of mitochondrial zeaxanthin and lutein may result in greater phospholipid oxidation and predispose to neurodegeneration.

Here, we have investigated whether non-toxic POVPC concentrations impair mitochondrial metabolism in differentiated (d)SH-SY5Y neuronal cells and whether there is any protective role for oxocarotenoids against mitochondrial dysfunction. After 24 hours, glutathione (GSH) concentration was lower in neuronal cells exposed to POVPC $(1-20 \mu \mathrm{M})$ compared with vehicle control without loss of viability compared to control. However, mitochondrial ROS production (determined by MitoSOX oxidation) was increased by $50 \%$ only after $20 \mu \mathrm{M}$ POVPC. Following delivery of lutein $(0.1-1 \mu \mathrm{M})$ and zeaxanthin $(0.5-5 \mu \mathrm{M})$ over 24 hours in vitro, oxocarotenoid recovery from dSH-SY5Y cells was $\geq 50 \%$. Coincubation with oxocarotenoids prevented loss of GSH after $1 \mu \mathrm{M}$ but not $20 \mu \mathrm{M}$ POVPC, whereas the increase in ROS production induced by $20 \mu \mathrm{M}$ POVPC was prevented by lutein and zeaxanthin.

Mitochondrial uncoupling increases and ATP production is inhibited by $20 \mu \mathrm{M}$ but not $1 \mu \mathrm{M}$ POVPC; carotenoids protected against uncoupling although did not restore ATP production.

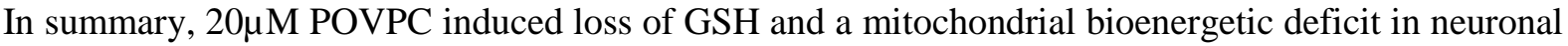
cells that was not mitigated by oxocarotenoids.

\section{Keywords}

Carotenoids, oxidative stress, mitochondria, viability, oxidised phospholipids, lutein, zeaxanthin, bioenergetics, POVPC 


\section{INTRODUCTION}

Reactive oxygen species (ROS) are produced during mitochondrial oxidative phosphorylation. Increased mitochondrial-derived ROS are associated with mitochondrial dysfunction and have been described as early events in neurodegenerative diseases [1-4]. In a vicious cycle of oxidative damage and ROS production, the oxidation of mitochondrial proteins, DNA and lipids precedes a decline in mitochondrial integrity. Several phospholipid oxidation products are cytotoxic at the site of production and have the potential to cross biological membranes of neighboring cells to exert distant effects [5-7]. This has been shown in cardiomyocytes, which are sensitive to exposure to cytotoxic oxPL and also accumulate mitochondrial OxPL during ischemia reperfusion and preceding cell death [8].

Carotenoids can quench singlet oxygen and scavenge other ROS without being consumed in the process except when scavenging peroxides [9-11]. While a Cochrane systematic review concluded that betacarotene supplements confer an increased risk of mortality [12], the oxygen-containing carotenoid hydrocarbons, xanthophylls, which include lutein, zeaxanthin and meso-zeaxanthin have shown more promise for positive health outcomes [11]. Lutein and zeaxanthin cannot be synthesized by humans and are obtained from the diet or supplements. The consumption of diet rich in fruits and vegetables as well as the modification of nutritional habits and lifestyle associates with higher oxocarotenoid levels in plasma and a lower risk of age-related diseases and AD [13]. Conversely, in the MARKAGE study, lower levels of $\beta$-cryptoxanthin and zeaxanthin were observed in the cognitively frail [14].

The discrete risk/benefit effects of carotenoids that have been observed in vivo may relate to their distinctive metabolism; oxocarotenoids are differentially distributed within subcellular compartments and are associated with specific metabolic enzymes [15]. In contrast to carotene which is metabolised by $\mathrm{BCO} 1$ and is retained in the cytoplasm, the enzyme $\mathrm{BCO} 2$ is associated with the inner mitochondrial membrane and metabolizes zeaxanthin (which accumulates in the inner mitochondrial membrane) into long-chain apo-carotenoids. $\mathrm{BCO} 2$ functions as a key regulatory enzyme that prevents toxicity caused by carotenoid accumulation and loss of $\mathrm{BCO} 2$ function is associated with the development of mitochondrial oxidative stress and metabolic diseases [16]. 
Others have shown that chronic administration of the oxocarotenoid lycopene significantly restores the mitochondrial respiratory enzyme activities in $A \beta 42$ treated rats and attenuated mitochondrial oxidative stress. These observations suggest a role for carotenoids in maintaining mitochondrial integrity in brain [17]. Our own work has shown that lutein, lycopene, and zeaxanthin concentrations were significantly lower in AD patients with vascular co-morbidities compared to healthy subjects [18]. In another study we have shown that the serum phospholipid oxidation product POVPC was higher in AD compared with age-matched control subjects but was not reduced by carotenoid supplementation in extant disease [19]. Taken together these studies indicate an inverse relationship between carotenoid concentration and the oxidised phospholipid POVPC in AD.

We hypothesise that during $\mathrm{AD}$ development, lower concentrations of systemic carotenoids are reflected by lower brain mitochondrial zeaxanthin and lutein, greater phospholipid oxidation and contribute to neurodegeneration via oxidative and metabolic stress. To investigate this hypothesis, here we have investigated any protective role for carotenoids against mitochondrial dysfunction induced by

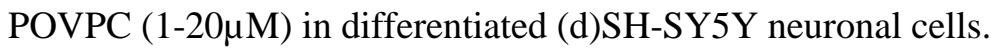




\section{MATERIALS AND METHODS}

Human neuroblastoma SH-SY5Y cells were purchased from American Type Culture Collections, Manassas, USA. Authentic standards of lutein and beta-apo-8'-carotenal were purchased from Sigma Aldrich (Dorset, UK); zeaxanthin was purchased from Cambridge Biosciences (Cambridge, UK); carotenoid standards were kept in the dark, made up fresh and used immediately after preparation and confirmation of concentrations. 1-palmitoyl-2-(5'-oxo-valeroyl)-sn- glycero-3-phosphocholine (POVPC) was purchased from Avanti Polar Lipids (Alabaster, AL, USA); MitoSOX ${ }^{\mathrm{TM}}$ Red was purchased from Invitrogen (Fisher Scientific, Loughborough, UK); cell titre blue was purchased from Promega Corporation (Hollow Road, USA). All materials for the Extracellular Flux assays were from Agilent Technologies / Seahorse Biosciences / (Santa Clara, USA). Carbonyl cyanide p[trifluoromethoxy]-phenyl-hydrazone (FCCP), oligomycin, and antimycin A were from Sigma-Aldrich. All solvents used were HPLC grade from Fisher Scientific (Loughborough, UK). All other cell culture media and chemicals were also purchased from Fisher Scientific (Loughborough, UK) unless otherwise stated.

\section{Cell culture}

\section{Routine cell culture}

SH-SY5Y cells were maintained routinely in RPMI 1640 media up to passage 20 and supplemented with heat inactivated $10 \%$ foetal bovine serum (FBS), $4 \mathrm{mM}$ L-glutamine and $200 \mathrm{U} / \mathrm{ml}$ penicillin and $200 \mu \mathrm{g} / \mathrm{ml}$ streptomycin at $37^{\circ} \mathrm{C}$ in a humidified atmosphere of $5 \% \mathrm{CO}_{2}$ and $95 \%$ air. Cells were seeded in a T75 flask at a density of $2 \times 10^{5}$ cells $/ \mathrm{ml}$.

\section{Differentiation of neuroblastoma cells}

Cells were differentiated into neuronal-like cells for 10 days and medium was replaced at least every 48 hours as described previously [1,20]. Briefly, SH-SY5Y cells were exposed to $10 \mu \mathrm{M}$ all-trans retinoic acid (RA) on day 1 after seeding. Medium was replaced with fresh RPMI routine culture medium containing RA every 48 hours. After 5 days the medium was changed to neurobasal media 


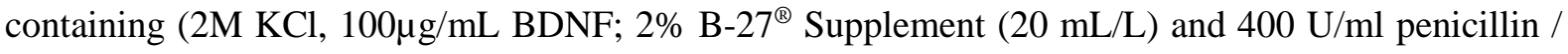
$400 \mu \mathrm{g} / \mathrm{ml}$ streptomycin) for an additional 5 days; medium was replaced every 48 hours.

SHSY5Y cell differentiation was measured by the extension of long neurites and the cessation of proliferation. The length of neurites was measured by image $\mathbf{J}$ software and a differentiated cell was defined as a cell with a neurite length greater than the length of the cell body (on average greater than $10 \mu \mathrm{m}$ in length). More than $80 \%$ SH-SY5Y cells displayed extended neurites after 10 day differentiation (Supplementary figure 1).

\section{Cell treatment with oxidised phospholipid and carotenoids}

After 10 days differentiation, SH-SY5Y cells were treated with POVPC $(0,1$ and $20 \mu \mathrm{M}) \pm$ carotenoids $\left(0.1,1\right.$ and $10 \mu \mathrm{M}$ lutein and $0.05,0.5$ and $5 \mu \mathrm{M}$ zeaxanthin) as indicated for 24 hours at $37^{\circ} \mathrm{C}$. Cells were washed with phosphate buffered saline (PBS) prior to analysis.

\section{Delivery of carotenoids to cells}

Plasma concentrations of lutein and zeaxanthin have been reported to be 0.3 and $0.1 \mu \mathrm{M}$ respectively [21]. Following up from our previous observations, we treated cells with lutein $(0.1$ and $1 \mu \mathrm{M})$ and zeaxanthin $(0.05,0.5$ and $5 \mu \mathrm{M})$ in agreement with Wagener et al. [22]. Carotenoid stock solutions were prepared in tetrahydrofuran (THF) [23] and further diluted (1:1000) with neurobasal media. The vehicle treatment had no effect on any analyses. The concentrations of lutein and zeaxanthin were estimated using Beer Lambert's law (Extinction coefficients in THF: Lutein-145100 1/(mol x cm); Zeaxanthin$144500 \mathrm{l} /(\mathrm{mol} \mathrm{x} \mathrm{cm})$.

\section{Extraction of carotenoids from cells}

To ascertain the uptake of carotenoids by dSHSY-5Y cells after 24h exposure, we extracted carotenoids from washed, treated cells, using the protocol adapted from Wagener et al. [22]. SH-SY5Y cells were seeded in $100 \mathrm{~mm}$ dishes at $2 \times 10^{6}$ cells/well, differentiated and then incubated in media containing different concentrations of lutein $(0-10 \mu \mathrm{M})$ and zeaxanthin $(0-5 \mu \mathrm{M})$ for 24 hours. The medium was then removed and cells were recovered by scraping in $1 \mathrm{ml}$ PBS. An aliquot of the sample was removed 
for protein assay (BCA). For HPLC, $500 \mu \mathrm{L}$ THF and $0.5 \mu \mathrm{M}$ internal standard (trans- $\beta$-apo-8'-carotenal) was added to the cells and ultrasonicated for 10 minutes. $3 \mathrm{~mL}$ hexane was used for the extraction of carotenoids and ultrasonicated for another 10 minutes. After centrifugation at $2000 \mathrm{~g}, 20^{\circ} \mathrm{C}$ for 10minutes, the organic phase was collected and the solvent was evaporated under nitrogen. The tube wall was rinsed with ether and allowed to dry for another 10 minutes. Pellets were re-suspended in $50 \mu 1$ THF and diluted with $100 \mu 1$ HPLC buffer (54\% methanol, 44\% acetonitrile, $2 \%$ propan-2-ol, 15\% water). Extraction was carried out in the dark.

\section{Assessment of metabolic activity}

Viability of cells and cytotoxicity of POVPC \pm carotenoids were estimated using a cell titre blue assay. SH-SY5Y cells were seeded in a 24 -well plate at $2 \times 10^{5}$ cells/well. After 10 days differentiation, cells were treated with POVPC \pm carotenoids for 24 hours. The cells were washed with PBS and incubated with media containing cell titre blue $\left(1: 5\right.$ dilution) in a $37^{\circ} \mathrm{C}$ incubator for $1-8$ hours, protected from light. The supernatant was removed into a 96-well plate and the fluorescence was measured at excitation/ emission wavelengths of 560/590nm in a SpectroMax GeminiXS microplate fluorometer (Molecular Devices, USA); with the diluted dye as the blank. The absolute fluorescent values were calculated and plotted against the concentrations of the treatments. Loss of metabolic activity was evaluated by comparing results to the control sample which was taken to be $100 \%$ metabolically active.

RNA isolation and SOD2 mRNA analysis

Total RNA was isolated using the Qiagen RNeasy Mini Kit according to the manufacturer's protocol. Briefly, SH5YSH cells were pelleted then suspended in RLT lysis buffer (provided) and homogenized by pipetting. To shear genomic DNA, the lysate was transferred to a gDNA spin column and centrifuged at $8000 \times \mathrm{g}$ that was primed with $70 \%$ (v/v) ethanol. The RNA was eluted adding $30 \mu \mathrm{L}$ of RNase-free water and purity was assessed by NanoDrop TM 1000/c (Spectrophotometers, Thermo Fisher Scientific,US). Quantitative PCR was then performed to determine SOD2 expression as previously described and using the following primers ( $\mathrm{f}=$ forward; $\mathrm{r}=$ reverse). 


\section{Human SOD2-f GTTCAATGGTGGTGGTCATATCA \\ Human SOD2-r GCAACTCCCCTTTGGGTTCT}

DNA isolation

Total DNA from SH5YSH cells was obtained using Qiagen DNeasy kit according to manufacturer's instructions. Briefly, the cell pellet was resuspended in $200 \mu \mathrm{l}$ of PBS, followed by proteinase K (provided). For efficient lysis, buffer AL was added to the cells at $56^{\circ} \mathrm{C}$ for 10 minutes. To precipitate DNA, 96-100\% ethanol was added, mixed by vortexing then transferred into a QIAamp mini column. After washing, samples were eluted from the column by centrifugation of the samples. DNA purity was detected by NanoDrop TM 1000/c (Spectrophotometers, Thermo Fisher Scientific,US). DNA copy number was analysed as described previously here using the primers for tRNA-Leu(UUR) relative to B2-microglobulin as housekeeper.

(https://currentprotocols.onlinelibrary.wiley.com/doi/abs/10.1002/0471142905.hg1907s68)

\begin{tabular}{|l|l|l|}
\hline Gene & & Primers \\
\hline tRNA-Leu(UUR) & Forward & CACCCAAGAACAGGGTTTGT \\
\hline & Reverse & TGGCCATGGGTATGTTGTTA \\
\hline B2-microglobulin & Forward & TGCTGTCTCCATGTTTGATGTATCT \\
\hline & Reverse & TCTCTGCTCCCCACCTCTAAGT \\
\hline
\end{tabular}

\section{Mitochondrial isolation from cells}

Mitochondria were isolated from dSH-SY5Y by cell disruption followed by differential centrifugation using a method adapted from Lampl et al. [46]. First, mitochondrial isolation buffer (MIB) (70mM 
sucrose, $210 \mathrm{mM}$ mannitol, $5 \mathrm{mM}$ HEPES, $1 \mathrm{mM}$ EGTA, pH 7.4) was prepared and stored at $4^{\circ} \mathrm{C}$. All procedures were performed at $4{ }^{\circ} \mathrm{C}$. For the isolation of mitochondria, two T75 flasks of cells per treatment were used. Cells were washed in cold PBS. Following, cells were scraped in cold PBS using a cell scraper and collected in $15 \mathrm{~mL}$ falcon tubes. Tubes were centrifuged for $5 \mathrm{~min}$ at $700 \mathrm{xg}, 4^{\circ} \mathrm{C}$. Supernatants were aspirated and cells were resuspended in $500 \mu \mathrm{L}$ of MIB. Cell suspensions were transferred to a Precellys tube containing silica beads. Following, the tissue was homogenised using a VelociRuptor V2 Microtube Homogeniser (Scientific Laboratories Supplies, UK) for 5 seconds. The homogenised solution was transferred to a $15 \mathrm{~mL}$ falcon tube and the solution was draw into a $5 \mathrm{~mL}$ syringe using a 19 gauge inch needle and expelled back into the tube using a 28 gauge inch syringe. This process was repeated 5 times. The solution was transferred to a $1.5 \mathrm{~mL}$ Eppendorf tube and centrifuged for 5 minutes at $600 \mathrm{x} \mathrm{g}, 4^{\circ} \mathrm{C}$. The supernatant was carefully removed and transferred to a new $1.5 \mathrm{~mL}$ Eppendorf tube. Supernatant was centrifuged for $10 \mathrm{~min}$ at $11,000 \mathrm{x} \mathrm{g}, 4^{\circ} \mathrm{C}$. The resulting supernatant was collected for cytosolic subcellular fractionation. The resulted pellet containing mitochondria was kept on ice.

Mitochondria were resuspended in 1X RIPA buffer containing protease and phosphatase inhibitors (Roche). Next, the mitochondria was homogenised by needle (10 times). Homogenate was centrifuged for $10 \mathrm{~min}$ at $10,000 \mathrm{xg}, 4^{\circ} \mathrm{C}$. Finally, the supernatant was collected and protein concentration was measured by BCA protein assay (Bio-Rad). A concentration of $30 \mu \mathrm{g}$ of protein was used to evaluate the protein carbonyl formation and $\alpha$-tubulin.

\section{Determination of cellular glutathione (GSH and GSSG) levels}

Total GSH and GSSG levels were estimated as an index of oxidative stress by the GSH recycling assay according to the method described by [24]. Briefly, dSH-SY5Y cells were seeded in 12 -well culture plates at $2 \times 10^{5}$ cells/well. After $24 \mathrm{~h}$ incubation, cells were scraped from the plate and washed twice with PBS. Sulfosalicylic acid (SSA; $3.33 \mu$ of $100 \%$ made up in distilled water) was added to the cell pellet and vortexed for 10 seconds. Stock buffer $(96.6 \mu \mathrm{l}$ of $125 \mathrm{mM}$ sodium phosphate, $6.3 \mathrm{mM}$ disodium EDTA, pH 7.5) was added to each tube, vortexed and centrifuged at $6600 \mathrm{~g}$ for $2.5 \mathrm{~min}$ and 
supernatants were collected carefully and stored immediately at $-80{ }^{\circ} \mathrm{C}$ prior to $\mathrm{GSH}$ analysis by $6 \mathrm{mM}$ DTNB (5,5'-dithiobis-(2-nitrobenzoic acid)) recycling assay. The yellow color was measured at $410 \mathrm{~nm}$ at $0,1,2,5$ and 10 minutes using the spectrophotometer.

\section{HPLC method development for carotenoid analysis}

Carotenoid analysis was carried out isocratically on an Agilent 1200 series high performance liquid chromatography (HPLC) instrument using a method adapted from [22]. Carotenoids were separated using a reversed phase Suplex pKb-100 HPLC Column 250x4.6mm, 5 $\mu \mathrm{m}$ (Sigma Aldrich). The mobile phase was $54 \%$ methanol, $44 \%$ acetonitrile, $2 \%$ (propan-2-ol, $15 \%$ water) at a flow rate of $1 \mathrm{~mL} / \mathrm{min}$. Extracted carotenoids $(99 \mu \mathrm{L})$ were injected onto the HPLC.

The HPLC system comprised of a thermostatically controlled autosampler, a quaternary pump and a variable wavelength detector (VWD). Lutein and zeaxanthin were detected at $450 \mathrm{~nm}$ and identified by their retention time and absorption spectrum compared with the characteristics of pure standards (>95\%). Quantification was performed using the Agilent chemstation (Version B.03.01-SR1) in relation to the internal standard. Concentrations were calculated by comparing the peak heights with standard reference curves. Standard chromatograms are shown in (Supplementary figure 2).

\section{Determination of linear dynamic range, LOD and LOQ of lutein and zeaxanthin}

An external calibration curve was prepared for lutein and zeaxanthin for the determination of their linear range, LOD and LOQ. Calibration curves were produced by injecting authentic solutions between 0.01 and $40 \mu \mathrm{M}$. The concentration ranges selected for the calibration curves were based on preliminary data on the dynamic ranges. LOD and LOQ were calculated using the visual evaluation method from the ICH guidelines [25] and are reported in Supplementary Table 1.

\section{HPLC method precision, accuracy and recovery}


Percentage recovery analysis was determined according to [26]. The recovery percentages were estimated by comparing the level of the carotenoid standards (lutein and zeaxanthin) with or without spiking into cells. Carotenoids were extracted as described earlier. We calculated recovery percentages for low, medium and high concentrations of lutein $(0.1,1,10 \mu \mathrm{M})$ and zeaxanthin $(0.05,0.5,5 \mu \mathrm{M})$. The accuracy of the method was determined for the optimum concentrations $(1 \mu \mathrm{M}$ lutein and $0.5 \mu \mathrm{M}$ zeaxanthin) by calculating the mean of the experimental values with the actual concentrations of the standards. Recovery was calculated for six replicates of each compound and presented as a percentage of initial material. Precision is required to be within $\pm 15 \%$ and accuracy between $85-115 \%$ [27]

\section{Analysis of POVPC levels}

Cellular POVPC levels were determined by mass spectrometry as detailed in Ademowo et al. [19]. Lipid extracts $(10 \mu \mathrm{l})$ were separated on an Acclaim C18 column (internal diameter $2.1 \mathrm{~mm}$, column length $150 \mathrm{~mm}$, particle size $3 \mu \mathrm{m}$, Thermo Scientific, UK) using the mobile phases consisted of (A) $10 \mathrm{mM}$ ammonium formate in methanol:water:formic acid (20:80:0.1, v/v/v) and (B) $2 \mathrm{mM}$ ammonium formate in 2-propanol:methanol:formic acid $(90: 10: 0.1, \mathrm{v} / \mathrm{v} / \mathrm{v})$ at $45{ }^{\circ} \mathrm{C}$. Flow rate was maintained at $100 \mu \mathrm{l} / \mathrm{min}$ with the gradient as follows: $30 \% \mathrm{~B}$ from 0 to $5 \mathrm{~min}, 30-70 \%$ B from 5 to $20 \mathrm{~min}, 70-100 \%$

B from 20 to $35 \mathrm{~min}, 100 \%$ B $35-40 \mathrm{~min}, 100-30 \%$ B from 40 to $41 \mathrm{~min}, 30 \%$ B $41-51 \mathrm{~min}$. The POVPC analyte eluted at $20.8 \mathrm{~min}$ while the ISTD, dPOPC eluted at $30.8 \mathrm{~min}$.

\section{Mitochondrial function assay}

Mitochondrial function of dSH-SY5Y cells was measured using Agilent Seahorse XF24 Extracellular Flux Analyzer that allows the determination of oxygen and proton concentrations in real time [28]. dSH-SY5Y cells were seeded in the XF24 culture plates at 80,000 cells/well, a day prior to treatment. Cells were treated with POVPC \pm carotenoid for 24 hours as indicated. On the day of assay, cells were incubated in assay medium containing ( $1 \mathrm{mM}$ sodium pyruvate, $2 \mathrm{mM}$ glutamine, $10 \mathrm{mM}$ glucose $)$ in a $\mathrm{CO}_{2}$-free incubator for 1 hour prior to the assay in order to de-gas solutions. The Seahorse protocol consisted of calibration/equilibration step, followed by the synchronised injection of drugs and reagents 
in each of three different ports. Ports were loaded with oligomycin - ATP synthase inhibitor, FCCP oxidative phosphorylation uncoupler; and a mixture of rotenone/antimycin A - inhibitors of respiratory complexes 1 and 111 respectively [29]. 3 min mix, 2 min wait and 3 min measure cycles were used; three baseline measurements were taken before and a subsequent three measurements were taken after drug additions. Data were expressed as the rate of oxygen consumption (OCR) in pmol/min. Cell numbers $(80,000$ cells/well), Oligomycin $(1 \mu \mathrm{M})$, FCCP $(1 \mu \mathrm{M})$ and antimycin A/Rotenone $(0.5 / 0.5 \mu \mathrm{M})$ concentrations were optimised prior to assay. Our optimum Seahorse reagent concentrations agree with Schneider et al. [1].

Respiratory parameters were measured by calculating respiration rates before and after the addition of electron transport chain inhibitors. The parameters calculated included ATP production (baseline respiration minus oligomycin post injection respiration); and proton leak (oligomycin respiration minus rotenone / antimycin A post injection respiration) [30]. Optimal concentrations of oligomycin, FCCP, and antimycin $\mathrm{A} /$ Rotenone were diluted in assay media and $75 \mu \mathrm{L}$ of each stock solution was loaded onto an XF24 cartridge. The microplate was loaded into the Seahorse XF24 analyser according to the manufacturer's instruction. Experiments were carried out at $37^{\circ} \mathrm{C}$. The OCR were automatically calculated, recorded, normalised with protein concentration and plotted by Seahorse XF24 software (Wave Desktop Version 2.4).

\section{MitoSOX oxidation analysis}

SH-SY5Y cells were seeded in a 24-well plate at $2 \times 10^{5}$ cells/well. After 10 days of differentiation, cells were treated with POVPC and carotenoids; POVPC $(1 \mu \mathrm{M}, 20 \mu \mathrm{M}, 50 \mu \mathrm{M})$ and carotenoids (lutein and zeaxanthin). 24 hours after the cells were POVPC \pm carotenoid treated, the cells were incubated with media containing $5 \mu \mathrm{M}$ MitoSOX Red Probe in a $37^{\circ} \mathrm{C}$ incubator for 10 minutes, protected from light. The media was removed and replaced with $0.5 \mathrm{~mL}$ measurement buffer (PBS with $\mathrm{Ca}^{2+} / \mathrm{Mg}^{2+}$ ). Fluorescence was measured with a microplate reader (510nm excitation / 595nm emission); with the measurement buffer as the blank. MitoSOX oxidation values were normalised against protein concentration and calculated as a percentage of the control. 


\section{Statistical analysis:}

Results are expressed as mean \pm standard error of mean (SEM). Statistical analysis was performed using Graphpad Prism software (version 7). One-way analysis of variance (ANOVA) was used to compare the effects of different concentrations of POVPC. The effects of carotenoid on cells were measured using two-way ANOVA. Post hoc comparisons between groups were made using Dunnett's multiple comparison test / Tukey's test. All results are means of three independent experiments performed in triplicates (except where otherwise stated) and $p<0.05$ was considered significant. 


\section{RESULTS}

\section{POVPC toxicity in dSH-SY5Y cells is associated with oxidative stress}

dSH-SY5Y cells were exposed to increasing concentrations of POVPC $(1,20 \mu \mathrm{M}$ and $50 \mu \mathrm{M})$ for 24 hours. Lower concentrations of POVPC did not affect viability, but significant cell death ( 25\%) was

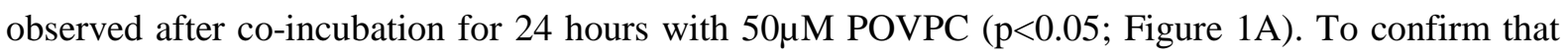
POVPC is taken up by neuronal cells, we analyzed the POVPC levels in cells before and after carotenoid supplementation by our multiple reaction monitoring (MRM) mass spectrometry method. Figure 1B confirms that POVPC is detectable in cells at different concentrations according to exposure,

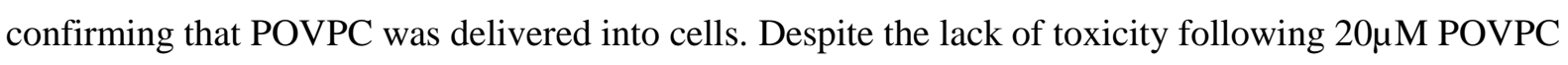
exposure, significantly increased concentrations of the oxPL were recovered in neurones after $24 \mathrm{~h}$ compared to untreated control cells (Figure 1B). At non-toxic concentrations of POVPC, a concentration-dependent increase in oxidative stress was observed, determined as a significant decrease in total glutathione levels after exposure to $\geq 1 \mu \mathrm{M}$ POVPC and a significant $\sim 50 \%$ increase in

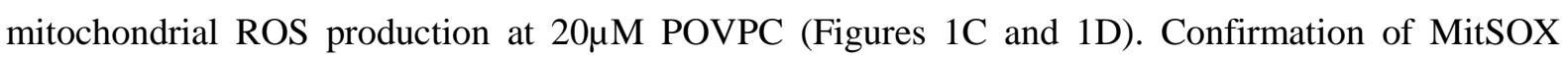
oxidation was achieved by microscopy (Supplementary Figure 3).

To understand whether mitochondria were oxidatively modified by POVPC after 24 hours treatment, we isolated mitochondria by centrifugation and analysed mitochondrial protein carbonyls by Western blot. There was a dose-dependent increase in protein carbonyl content as determined by Image $\mathrm{J}$ analysis that was more evident in some lower MW bands than others (Figures 1E). In both experimental replicates, the tubulin housekeeping band intensity was lower after $20 \mu \mathrm{M}$ POVPC treatment, for equivalent protein loading (Figure 1F). 

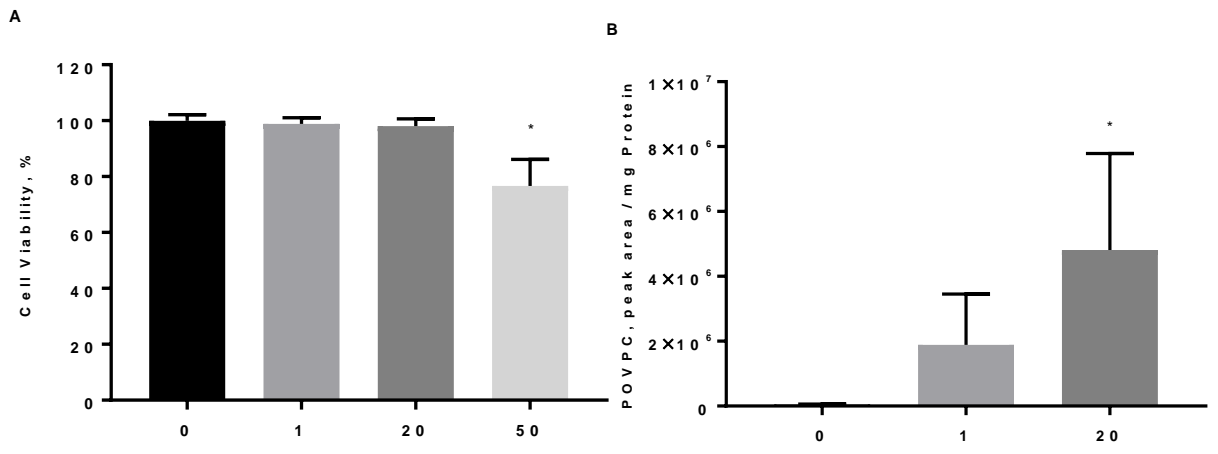

POVPC concentration, $\mu \mathrm{M}$

POVPC concentration, $\mu M$
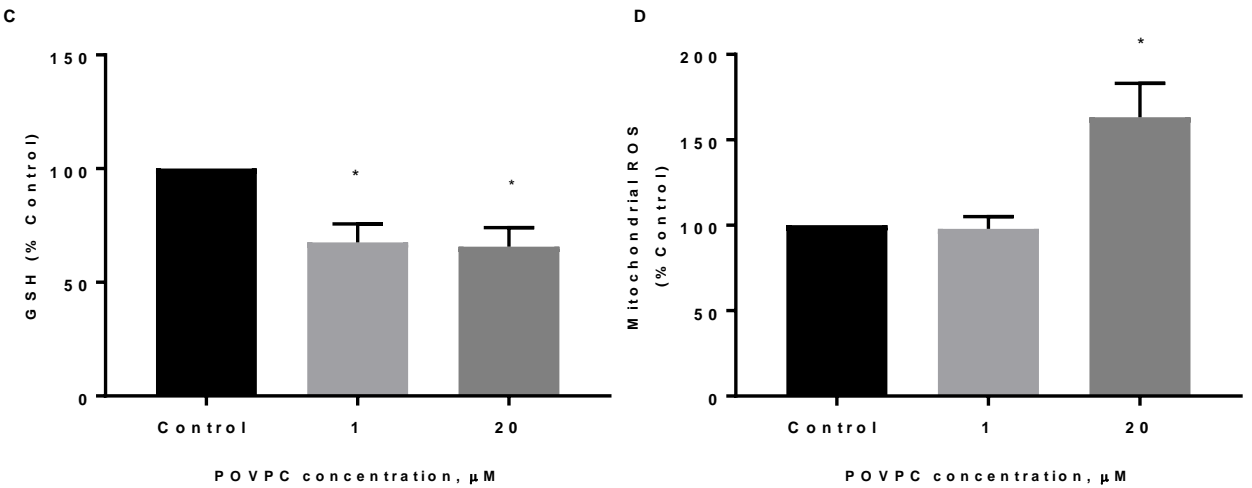

$\mathrm{E}$

$\mathrm{F}$

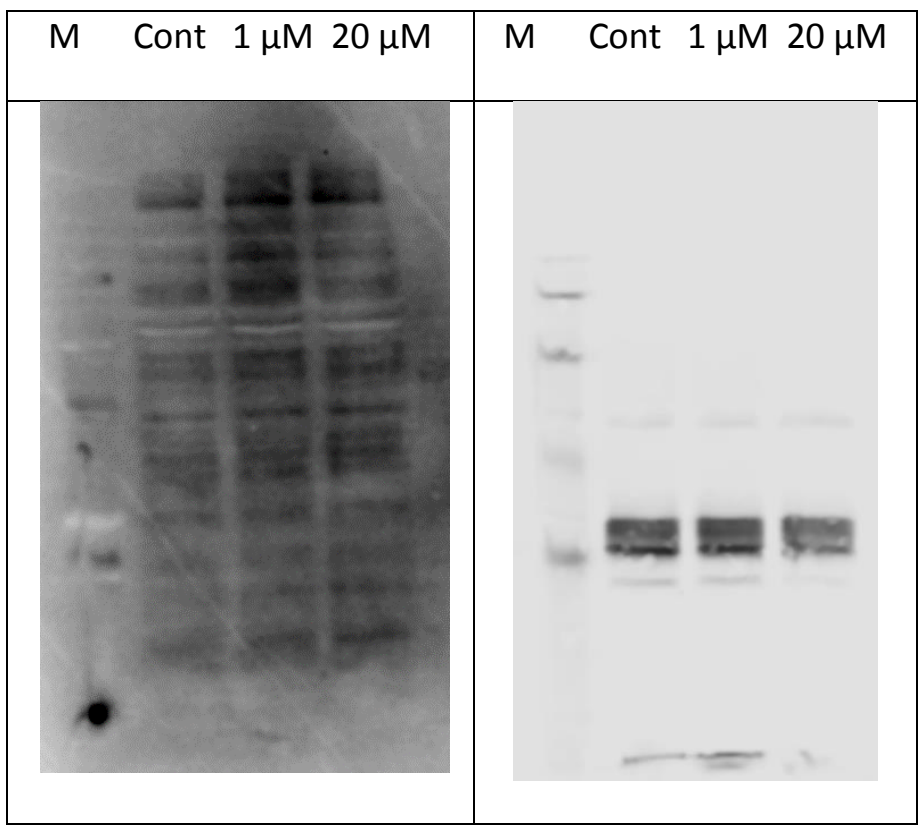

Figure 1. Exposure of dSH-SY5Y cells to POVPC decreases cell viability, causes toxicity and oxidative stress in a concentration-dependent manner over 24 hours. Data (A-D) are expressed as 
means \pm SEM of 3 independent assays and in triplicates and differences were evaluated by ANOVA. ${ }^{*} \mathrm{p} \leq 0.05$ compared to untreated control. Figure $1 \mathrm{E}$ and $1 \mathrm{~F}$ are representative of two independent blots of mitochondrial proteins stained for protein carbonyls (1E) with mitochondrial tubulin as a loading control (1F).

\section{Carotenoid uptake and antioxidant activity in dSHSY5Y}

To confirm that carotenoids were taken up by neuronal cells, cells were lysed after 24-hour incubation in the presence of increasing concentrations of lutein or zeaxanthin. We were not able to detect lutein in cells treated with low concentrations of the carotenoid $(0.1 \mu \mathrm{M})$ possibly reflecting its consumption to below detectable levels over 24 hours; however, at $1 \mu \mathrm{M}$ lutein recovery was estimated at $72.8 \%$ (Table 1). Similarly, at the lowest concentration of zeaxanthin investigated $(0.05 \mu \mathrm{M})$ we were not able to detect any uptake into cells, however, at 0.5 and $5 \mu \mathrm{M}$ zeaxanthin, 80 and $43.6 \%$ uptake were measured.

Table 1: Precision, accuracy and \% recovery of carotenoids from SHSY5Y cells

\begin{tabular}{|c|c|c|c|c|c|}
\hline Carotenoid & $\begin{array}{l}\text { Concentration } \\
\text { added }(\mu \mathrm{M})\end{array}$ & $\begin{array}{l}\text { Concentration } \\
\text { recovered } \\
(\mu \mathrm{M})\end{array}$ & \% Recovery & $\begin{array}{l}\text { Accuracy } \\
(\%)\end{array}$ & $\% \mathrm{CV}$ \\
\hline \multicolumn{6}{|l|}{ Lutein } \\
\hline & 0.0 & 0.0 & 0.0 & & \\
\hline & 0.1 & 0.0 & 0.0 & & \\
\hline & 1.00 & $0.73 \pm 0.03$ & 72.8 & 90.0 & 5.81 \\
\hline \multicolumn{6}{|l|}{ Zeaxanthin } \\
\hline & 0.0 & 0.0 & 0.0 & & \\
\hline & 0.05 & 0.0 & 0.0 & & \\
\hline & 0.5 & $0.40 \pm 0.02$ & 80.3 & 106.0 & 6.86 \\
\hline
\end{tabular}




\section{$5.0 \quad 2.18 \pm 0.14 \quad 43.6$}

$\mathrm{n}=6$

HPLC chromatograms and calibration curves are shown in supplemental Table 1 . The accuracy was 90$106 \%$ and \% CV of 5-7\% [27]. The limit of detection (LOD) for lutein, zeaxanthin and the internal standard are $0.1,0.1$ and $0.05 \mu \mathrm{M}$ respectively while the limit of quantification (LOQ) for lutein, zeaxanthin and the internal standard are $0.5,0.5$ and $0.2 \mu \mathrm{M}$ respectively.

Following coincubation of dSHSY-5Y cells with lutein $(0.1$ and $1 \mu \mathrm{M})$, there was no loss of viability (Figure 2A). In addition, there was a significant decrease in mitochondrial ROS production (Figure 2C) without effect on total GSH (Figure 2B). Interestingly, the presence of POVPC increased expression of the mitochondrial antioxidant enzyme, SOD2 (Figure 2D). 
A

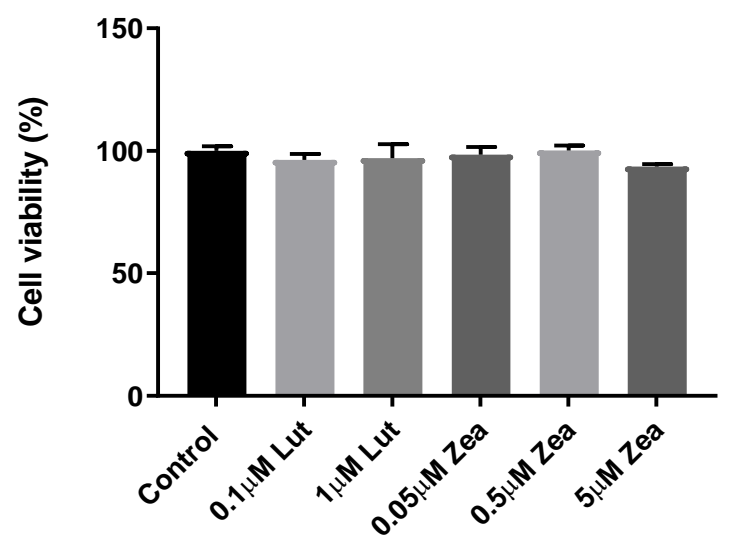

C

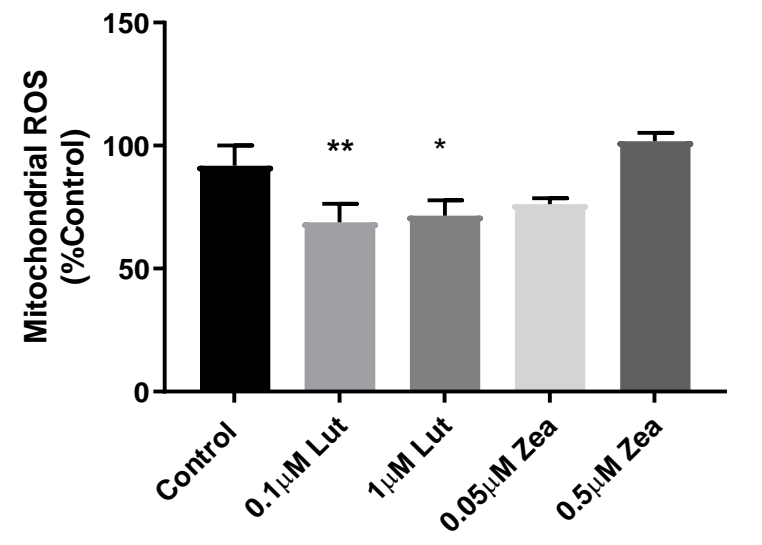

B

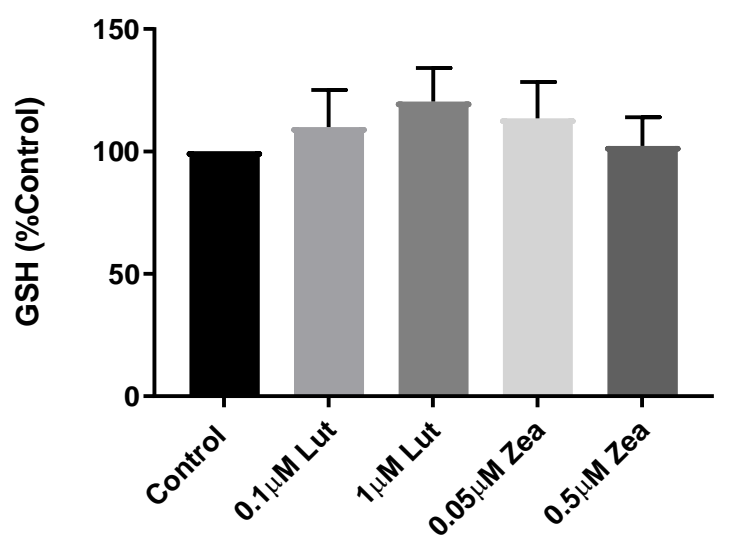

D

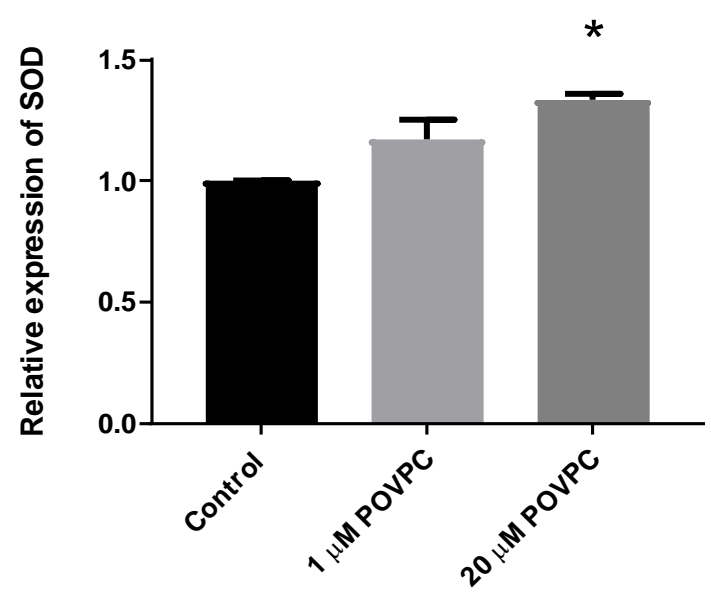

Figure 2. Exposure of dSH-SY5Y cells to carotenoid reduced oxidative stress over 24 hours. Data are expressed as means \pm SEM of 3 independent assays and in triplicates and differences were evaluated by one way ANOVA. *p $\leq 0.05$ compared to untreated control

Carotenoids partially protect against toxicity and oxidative stress induced by POVPC in dSHSY5Y cells

In order to investigate any protective effect of carotenoids against POVPC-induced oxidative stress, we determined cell viability and intracellular total GSH in dSH-SY5Y cells treated with POVPC in the presence or absence of carotenoids for 24 hours. The combination of POVPC and carotenoids did not 
affect cell viability over the concentration ranges used here (Figure $3 a$ and $b$ ). Both carotenoids were protective against the loss of GSH induced by 1uM POVPC but had no effect on the changed cellular GSH levels due to $20 \mu \mathrm{M}$ POVPC. GSSG concentration was almost doubled by 20 but not $1 \mu \mathrm{M}$ POVPC and in the presence of lutein or zeaxanthin $(0.05 \mu \mathrm{M})$ alone, GSSG concentration was halved Figure $3 \mathrm{D})$.

A

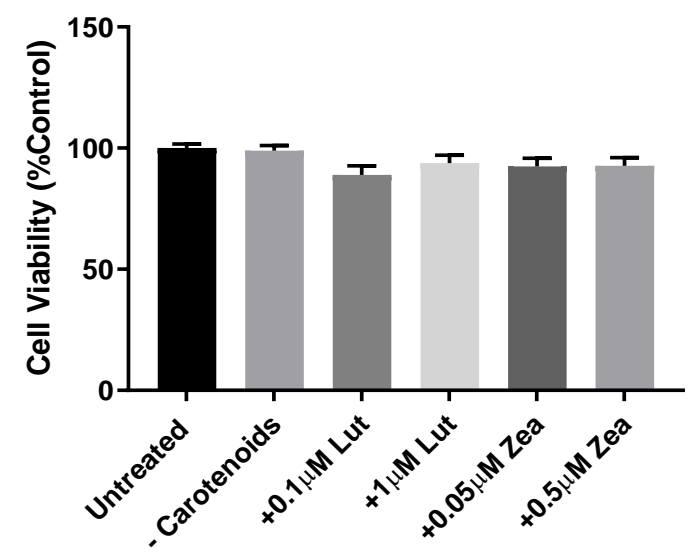

$1 \mu \mathrm{M}$ POVPC

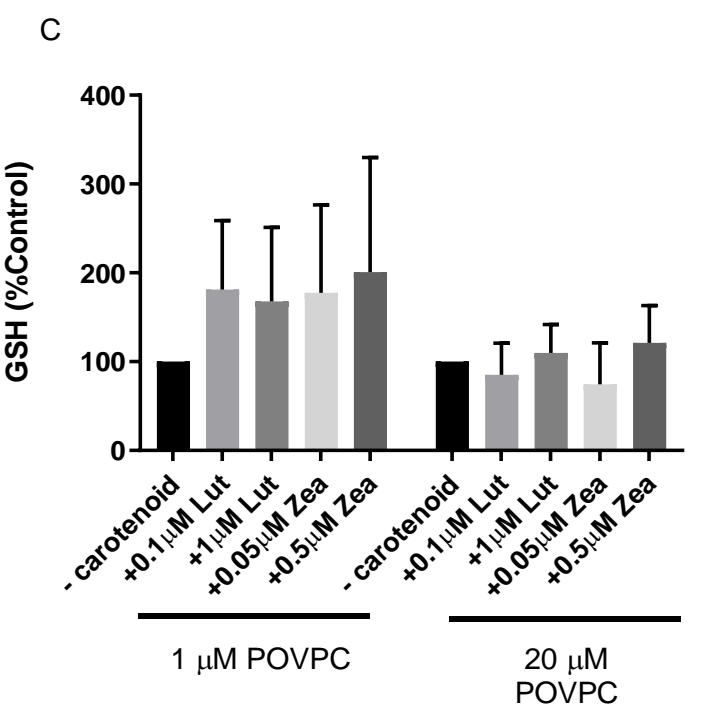

B

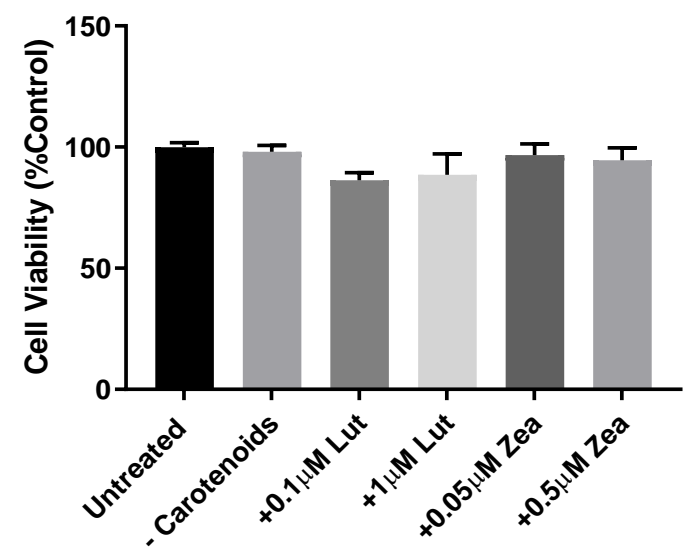

$20 \mu \mathrm{M}$ POVPC

D

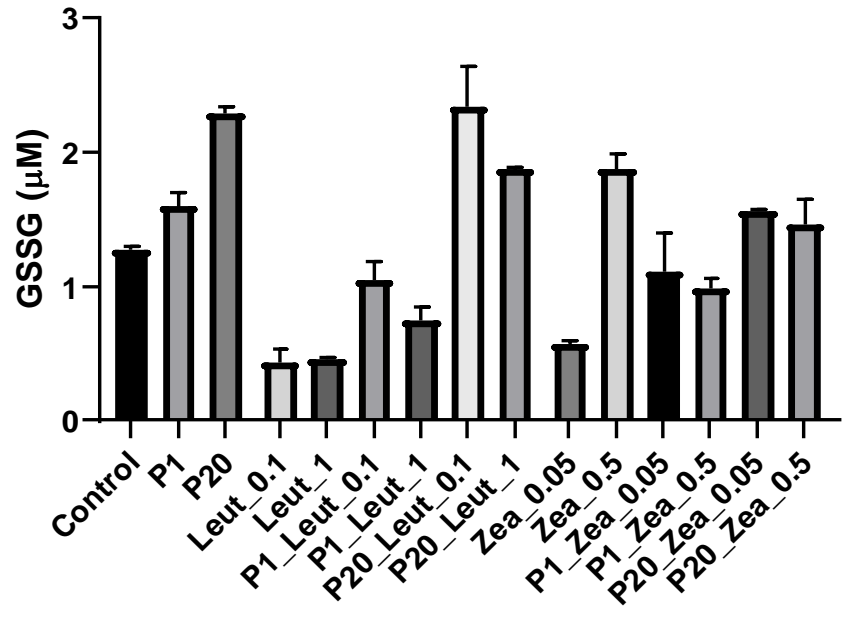


Figure 3. Effect of carotenoids on POVPC-induced loss of total GSH, GSSG levels and viability. Data are expressed as means \pm SEM of 3 independent assays and in triplicates apart from GSSG thatw as determined in duplicate.

\section{Effects of carotenoids on POVPC-induced mitochondrial ROS}

To ascertain whether carotenoids protected against POVPC-induced mitochondrial ROS production, MitoSOX red, a mitochondrial superoxide indicator was used. Figure 4 confirms that the presence of carotenoids reduced mitochondrial stress by $\sim 50 \%$ in the presence of $20 \mu \mathrm{M}$ POVPC compared to

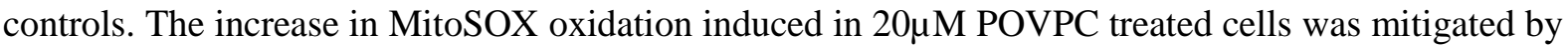
the presence of any carotenoid treatment whereas no significant effect was seen at lower POVPC concentrations.

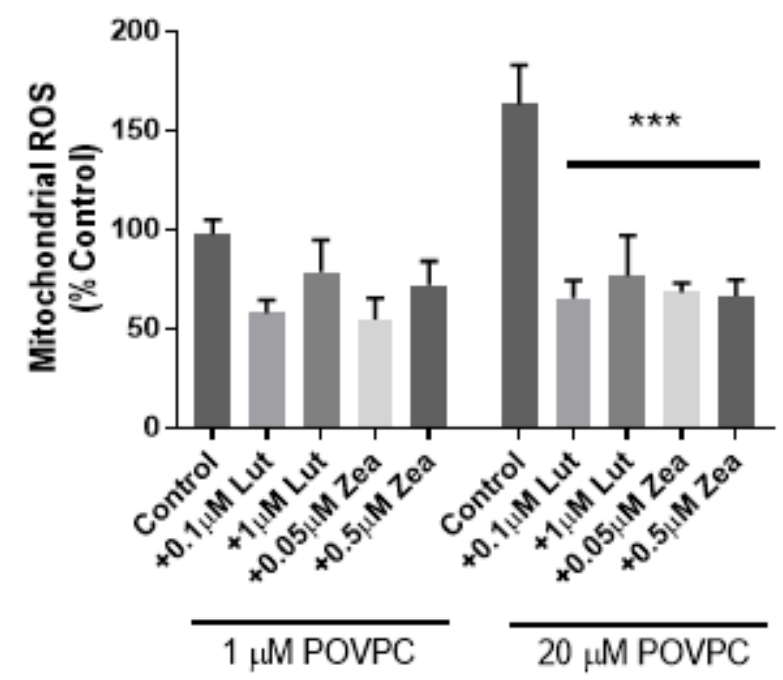

Figure 4. Carotenoids protect against of POVPC $(20 \mu \mathrm{M})$ induced MitoSOX oxidation in dSHSY5Y cells. Data are expressed as means \pm SEM of 3 independent assays and in triplicates and differences were evaluated by ANOVA. $* * * \mathrm{P}<0.001$ compared to no carotenoid control

Effects of POVPC and carotenoids on mitochondrial respiration in neuronal cells 
Mitochondria serve as important stores for intracellular GSH which in turn protect from uncoupling and apoptosis. From earlier experiments, we have confirmed oxidative stress was induced with 1 and $20 \mu \mathrm{M}$ POVPC concentrations and showed some protective effects of carotenoids against POVPC. We therefore analysed mitochondrial respiration using the Seahorse Extracellular Flux Analyser in neurones treated with different concentrations of POVPC and carotenoids. Figure 5A shows that $1 \mu \mathrm{M}$ POVPC treatment did not significantly affect mitochondrial function. However, $20 \mu \mathrm{M}$ POVPC- treated cells showed significant proton leak which associated with POVPC concentration dependent loss of ATP production. While apparent proton leak induced by $20 \mu \mathrm{M}$ POVPC was prevented by zeaxanthin and lutein (Figure 5A), ATP production was not significantly rescued with carotenoid supplementation Figure 5B. In order to evaluate whether this effect was due to mitochondrial number, we determined copy number. There was no effect of POVPC treatment due to change in mitochondrial content in cells (Figure 5C).

A

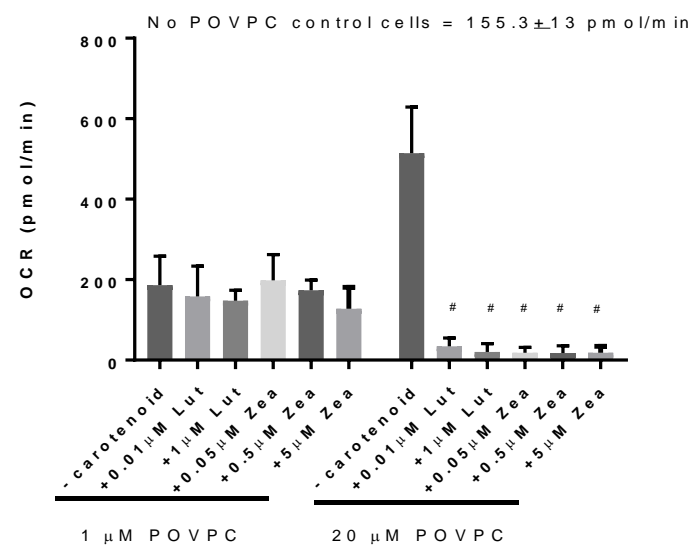

C

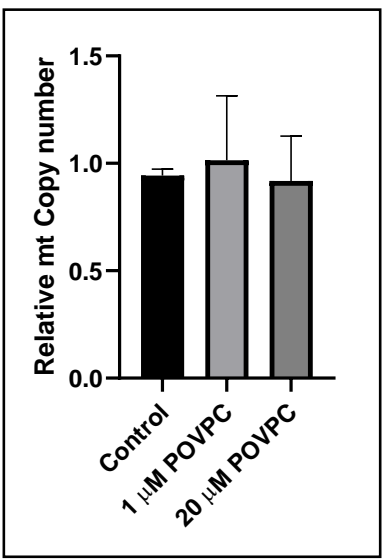

B

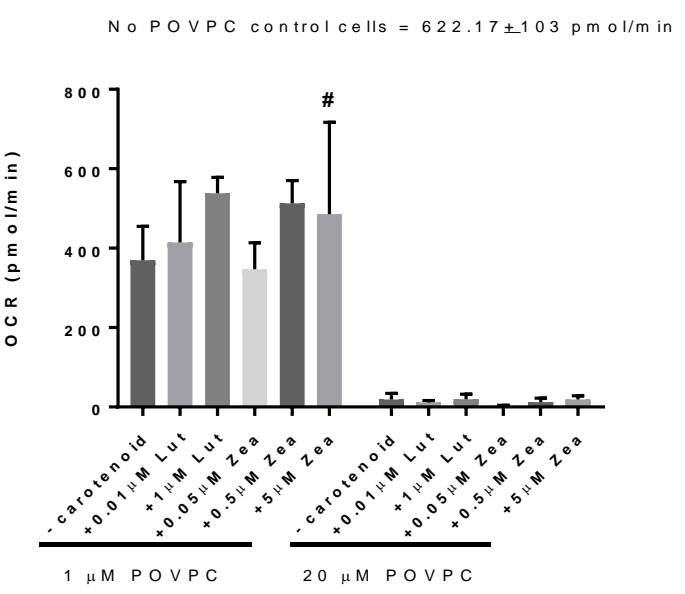


Figures 5. Mitochondrial stress test of SH-SY5Y cells treated with POVPC and carotenoids. Data are expressed as means \pm SEM of 3 independent assays and differences were evaluated by ANOVA \# $\mathrm{p} \leq 0.0001$ compared to no carotenoid control; $\# \mathrm{p}<0.05$ compared to no carotenoid control.

\section{DISCUSSION}

Cross-sectional studies have shown that plasma oxocarotenoid concentrations correlate positively with cognitive function in older adults $[9,13,18,31,32]$. In addition, dietary patterns of higher oxocarotenoid dietary intake associate with lower risk for cognitive decline in cohort studies. It is known that oxocarotenoids can act as antioxidants in vitro; however, few have investigated the underlying mechanism in detail. Here we have shown for the first time that lutein and zeaxanthin are taken up by neuronal cells and protect neuronal mitochondria from loss of function induced by the OxPL, POVPC. These findings suggest that mitochondrial function merits investigation as a biomarker of oxocarotenoid benefit.

Previous studies showed that exogenous POVPC is toxic as it is readily internalized, migrates to and damages the mitochondria [5]. Neurones rely on mitochondria to meet energy demands, and dysfunction of oxidative phosphorylation associates with several neurological disorders. In addition, mpaired mitochondrial function is frequently observed in neurodegenerative diseases such as Alzheimer's disease [33-35]. Others have shown that POVPC could induce oxidative stress and impairs mitochondria function in a dose-dependent manner; 50 $\mu \mathrm{M}$ oxidised phospholipid (PGPC and POVPC) induced apoptosis in macrophages [6,36].

Our study shows for the first time that the oxPL POVPC $(1 \mu \mathrm{M})$ induced neuronal oxidative stress while preserving metabolic function in vitro, however, a higher sublethal concentration of POVPC $(20 \mu \mathrm{M})$ caused mitochondrial proton leak, loss of GSH, an increase in SOD2 expression and inhibition of mitochondrial ATP production. The decrease in metabolic activity that we observed with $\geq 20 \mu \mathrm{M}$ POVPC agrees with previous studies of Stemmer et al. [6].

The uptake, distribution and metabolism of carotenoids have been attributed to the activities of different protein transporters (SR-BI, CD36, NPC1L1), digestion enzymes (PNLIP, CES), cleavage enzymes 
(BCO1/2), intracellular transporters (FABP2) and receptors (LPL, APOC/E, LDLR). It is predicted that carotenoids are bioavailable for many cell types [37]. Using recovery studies, here we have confirmed the uptake of carotenoids by (d)SHSY5Y cells.

The differential distribution and specificity of carotenoid cleavage enzymes, BCO 1 and 2 led us to speculate that mitochondria may be an important target for neuronal protection by oxocarotenoids, because lutein and zeaxanthin are metabolised by $\mathrm{BCO} 2$ which is located within mitochondria.

The Seahorse Extracellular flux analysis has emerged as a powerful tool to study mitochondrial bioenergetics [29] suggesting possible causes of mitochondrial dysfunction and an in-depth understanding of metabolic pathways, signals, and phenotypes and enables the calculations of mitochondrial and non-mitochondrial respiration. Exposure of cells to POVPC with and without carotenoids inhibited mitochondrial respiration. Proton leak and ATP production efficiency were significantly impaired in a dose-dependent manner. Proton leak and non-mitochondrial respiration (data not shown) was higher in $20 \mu \mathrm{M}$ POVPC treated cells compared to $1 \mu \mathrm{M}$ POVPC treated cells. This observation was independent of copy number suggesting the absence of mitophagy at the concentrations of POVPC studied here. However, we did observe an increase in protein carbonyl formation in mitochondria isolated from POVPC treated cells, suggesting they may be susceptible to oxidative damage.

Here, we showed that delivering zeaxanthin and lutein at concentrations similar to those seen in plasma was able to protect against mitochondrial proton leak and ROS production but did not mitigate against loss of glutathione or loss of mitochondrial ATP production by higher POVPC $(20 \mu \mathrm{M})$ concentration. Despite preventing proton loss, carotenoids could not restore mitochondrial ATP production in cells exposed to higher POVPC concentrations, probably due to sustained GSH depletion. Oxidised GSH is depleted from cells by transport extracellularly when its capacity for reduction is exceeded. It is possible that the loss of ATP may reflect a switch of cell metabolism towards the pentose phosphate pathway, away from mitochondria, to produce NADPH and enable effective reduction of GSH.

Neurones have high energetic requirements, primarily using glucose as the energy substrate. They are highly susceptible to alteration of mitochondrial function leading to glucose hypometabolism [38]. It 
has been proposed that maintaining mitochondrial metabolism may support neuronal survival. In support of this, metformin administration improves neuronal survival and mitochondrial function in preclinical studies of Alzheimer's disease (AD) [39].

Previous studies have shown that mitochondrial-targeted antioxidants are capable of maintaining blood flow, mitochondrial function and physiological redox state in mice [40], again supporting the hypothesis that ROS may arise from and lead to mitochondrial dysfunction. The mechanism by which lutein and zeaxanthin protect neuronal tissue against degenerative diseases has been suggested to be due to their lipid-soluble singlet-oxygen quenching antioxidant property which is related to their localisation and orientation within the lipid membrane [41,42].

Carotenoids such as lutein and zeaxanthin are able to penetrate membranes due to their lipophilicity and may be able to restore mitochondrial function under low stress conditions [11]. Carotenoids are effective modulators of the physical properties of both natural and model membranes, increasing their rigidity and thermostability [43]. Oxo-carotenoids stabilize membranes to a greater extent than $\beta$ carotene; they are incorporated into bilayers and span the membrane with their lipophilic core, being further anchored in the aqueous area with $-\mathrm{OH}$ groups, thus functioning like a molecular rivet $[43,44]$. Our observation that oxocarotenoids counteract POVPC-dependent proton leakage presents the possibility that POVPC may otherwise target and disrupt physical properties of the mitochondrial membrane causing loss of membrane stability and function.

Bohn, [31] reviewed the strength of evidence between carotenoid intake and changes in oxidative stress in human observational studies and intervention trials in health and diseases, proposing that circulating levels of carotenoids can be used as markers for total mortality. We and others have shown inverse correlations between plasma concentrations of lycopene, lutein, zeaxanthin, meso-zeaxanthanin but not carotene with circulating levels of peroxidised lipids in dementia patients. In older adults, lutein and zeaxanthin supplementation have been shown recently to facilitate the brain capacity for cognitive compensation in an fMRI study of healthy ageing; this showed the integration between different networks that are functionally segregated earlier in the lifespan. This study lends some credence to the 
concept that any protective effect of oxocarotenoids on cognitive function should be evaluated in prodromal stages of disease [45].

\section{CONCLUSION}

Physiological concentrations of oxidized phospholipid induced neuronal oxidative stress, but not a bioenergetic deficit, that can be mitigated by the xanthophyll carotenoids in a dose dependent manner.

However, delivery of carotenoids did not protect neuronal cells from elevated oxidised phospholipid concentrations, probably due to GSH depletion and mitochondrial dysfunction.

\section{ACKNOWLEDGEMENTS}

OSA was supported by the Aston Research Centre for Healthy Ageing.

HKID and HRG gratefully acknowledge support from the Kidney Research Foundation PDF3/2014.

HKID also acknowledges support from Alzheimer's Research UK network grant LES811839.

\section{CONFLICT OF INTEREST/ DISCLOSURE STATEMENT}

The authors have no conflict of interest to report. 
SUPPLEMENTARY FILE 


\section{Supplementary Figure 1}

SHSY5Y cells

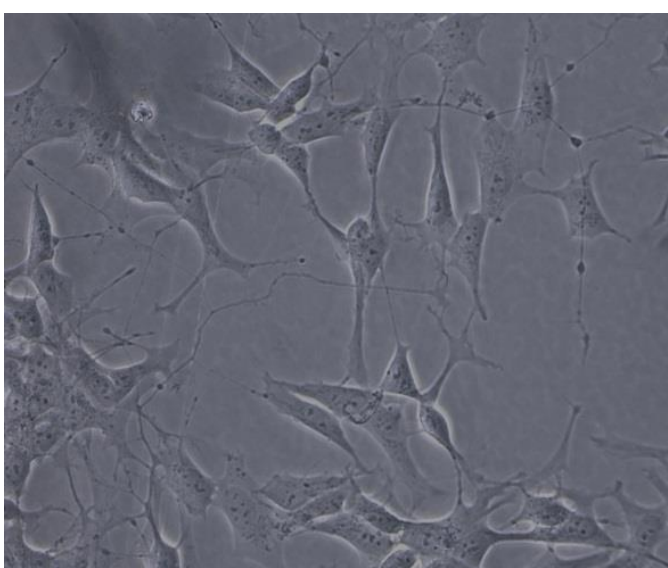

dSHSY5Y cells (day 10)

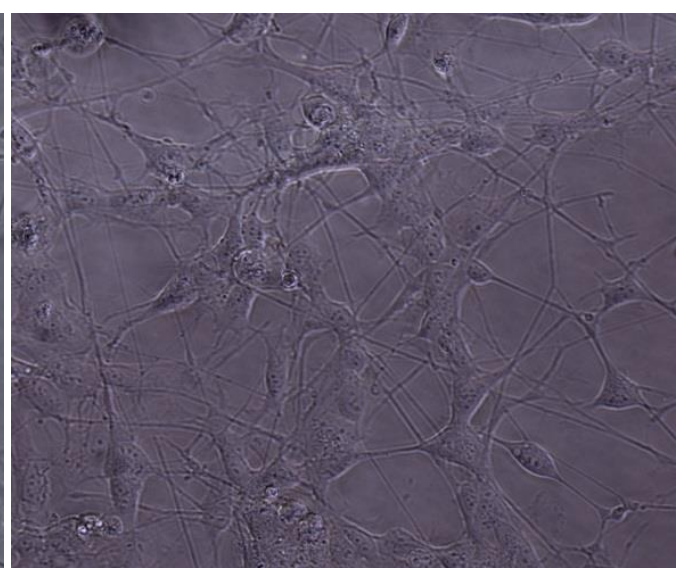

Light microscopy images of SHSY5Y cells with and without differentiation for 10 days with retinoic acid 


\section{Identification of carotenoids with HPLC}

A

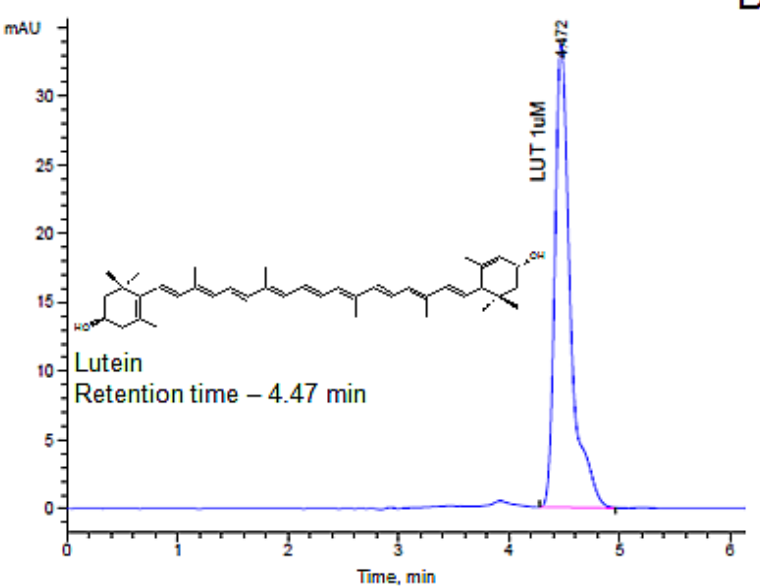

C
B

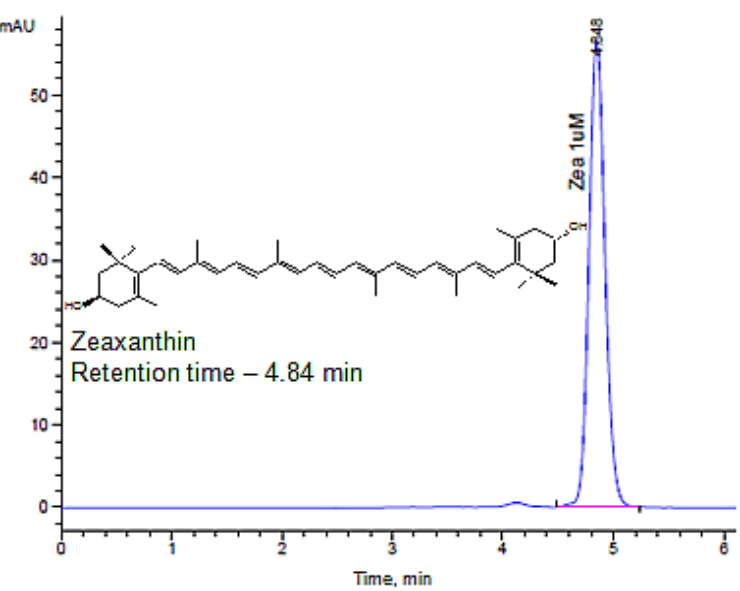

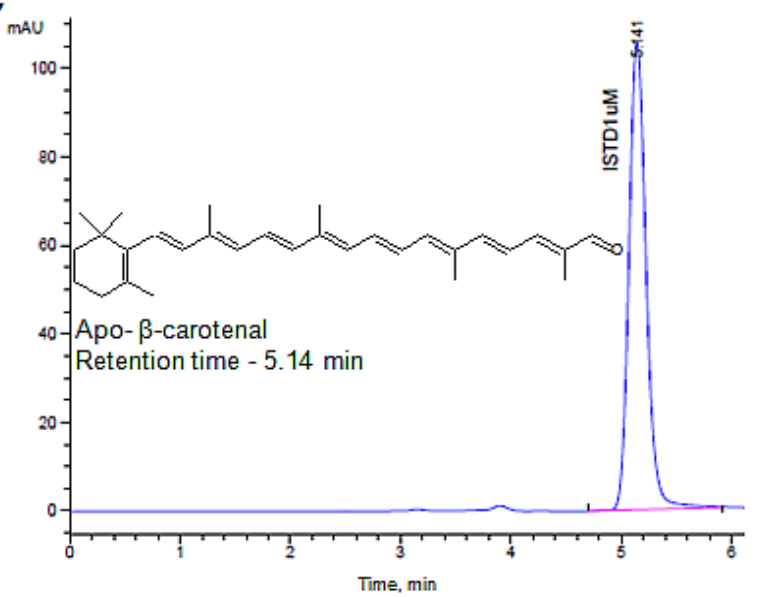

\section{Supplementary Figure 2}

The structures and the chromatograms for A) lutein $\left(\mathrm{C}_{40} \mathrm{H}_{56} \mathrm{O}_{2}\right)$, B) zeaxanthin $\left(\mathrm{C}_{40} \mathrm{H}_{56} \mathrm{O}_{2}\right)$ and C) Apo$\beta$-carotenal $\left(\mathrm{C}_{30} \mathrm{H}_{40} \mathrm{O}\right)$. Lutein eluted at $4.47 \mathrm{~min}$, zeaxanthin eluted at $4.84 \mathrm{~min}$ and the internal standard, apo- $\beta$-carotenal eluted at 5.14min under isocratic conditions. The hydroxyl group at the C-3' position in lutein (3R, $3^{\prime} R, 6^{\prime} R-\beta, \varepsilon$-carotene-3,3'-diol) is configured exactly opposite to that of zeaxanthin (3R, $3^{\prime} \mathrm{R}-\beta, \beta$-carotene-3,3'-diol). 


\section{Visualisation of mitochondrial ROS using mitoSOX}

MitoSOX Fluorescence

SH5YSH cells were seeded in a 24 culture well plate at $2 \times 10^{5}$ cell $/ \mathrm{ml}$ as described above until confluent. After treatment, medium was replaced by DAPI (diamidinophenylindole, Abcam) in 1:10 dilution in fresh medium with an incubation of 10 minutes at $37^{\circ} \mathrm{C}$. Subsequently, $5 \mu \mathrm{M}$ MitoSOX (Sigma) in RPMI medium was added to the wells and incubated for 20 minutes. The medium was removed and cells were washed twice with PBS 1x and resuspended in fresh medium. Fluorescence image stained was visualized by Nikon (Ti-E live cell imaging system, UK) and the analysis by Image J 1.80 software (NIH).

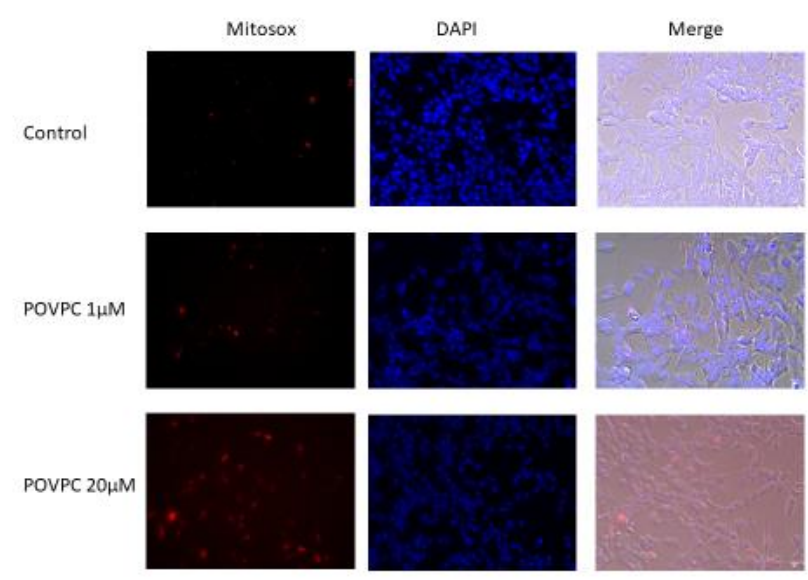

Supplementary Figure 3. Mitochondrial ROS production is more frequent in dSHSY5Y cells after treatment with POVPC for 24 hours 
LOD, LOQ and the calibration curve obtained from carotenoid standards

\begin{tabular}{lllll}
\hline & LOD & LOQ & \multicolumn{2}{c}{ Calibration curve } \\
\hline Carotenoid standards & $(\boldsymbol{\mu M})$ & $(\boldsymbol{\mu M})$ & Equation & $\boldsymbol{R}$ \\
\hline Lutein & 0.1 & 0.5 & $\mathrm{y}=28.37 \mathrm{x}+3.881$ & 0.999 \\
Zeaxanthin & 0.1 & 0.5 & $\mathrm{y}=45.12 \mathrm{x}-2.021$ & 0.998 \\
Apo- $\boldsymbol{\beta}$-carotenal & 0.05 & 0.2 & $\mathrm{y}=82.65 \mathrm{x}+30.980$ & 0.998 \\
\hline
\end{tabular}

\section{Supplementary Table 1}

LOD and LOQ were calculated using the visual determination, expressed as the analyte concentration.

$\mathrm{R}$ is the correlation coefficient, $\mathrm{x}$ is the injected amount in $\mu \mathrm{M}$ and $\mathrm{y}$ is the peak height. Calibration curves were produced by injecting $0.01,0.05,0.1,0.5,1,2,5,10,15,20,25,30$ and $40 \mu \mathrm{M}$ of the analytes. Lutein and zeaxanthin were linear between $0-40 \mu \mathrm{M}$ while the internal standard (Apo- $\beta$-carotenal) was linear between $0-30 \mu \mathrm{M}$. 


\section{REFERENCES}

[1] Schneider L, Giordano S, Zelickson BR, S. Johnson M, A. Benavides G, Ouyang X, Fineberg N, Darley-Usmar VM, Zhang J (2011) Differentiation of SH-SY5Y cells to a neuronal phenotype changes cellular bioenergetics and the response to oxidative stress. Free Radic. Biol. Med. 51, 2007-2017.

[2] Rego AC, Oliveira CR (2003) Mitochondrial Dysfunction and Reactive Oxygen Species in Excitotoxicity and Apoptosis: Implications for the Pathogenesis of Neurodegenerative Diseases. Neurochem. Res. 28, 1563-1574.

[3] Aufschnaiter A, Kohler V, Diessl J, Peselj C, Carmona-Gutierrez D, Keller W, Büttner S (2017) Mitochondrial lipids in neurodegeneration. Cell Tissue Res. 367, 125-140.

[4] Paradies G, Paradies V, Ruggiero FM, Petrosillo G (2017) Mitochondrial bioenergetics decay in aging: beneficial effect of melatonin. Cell. Mol. Life Sci. 1-15.

[5] Chen R, Yang L, McIntyre TM (2007) Cytotoxic Phospholipid Oxidation Products. J. Biol. Chem. 282, 24842-24850.

[6] Stemmer U, Dunai ZA, Koller D, Pürstinger G, Zenzmaier E, Deigner HP, Aflaki E, Kratky D, Hermetter A (2012) Toxicity of oxidized phospholipids in cultured macrophages. Lipids Health Dis. 11, 110.

[7] Moumtzi A, Trenker M, Flicker K, Zenzmaier E, Saf R, Hermetter A (2007) Import and fate of fluorescent analogs of oxidized phospholipids in vascular smooth muscle cells. J. Lipid Res. $\mathbf{4 8 ,}$ $565-82$.

[8] Yeang C, Hasanally D, Que X, Hung M-Y, Stamenkovic A, Chan D, Chaudhary R, Margulets V, Edel AL, Hoshijima M, Gu Y, Bradford W, Dalton N, Miu P, Cheung DY, Jassal DS, Pierce GN, Peterson KL, Kirshenbaum LA, Witztum JL, Tsimikas S, Ravandi A (2019) Reduction of myocardial ischaemia-reperfusion injury by inactivating oxidized phospholipids. Cardiovasc. Res. 115, 179-189. 
[9] Fiedor J, Burda K (2014) Potential role of carotenoids as antioxidants in human health and disease. Nutrients 6, 466-88.

[10] Block G, Patterson B, Subar A (1992) Fruit, vegetables, and cancer prevention: a review of the epidemiological evidence. Nutr. Cancer 18, 1-29.

[11] Bernstein PS, Li B, Vachali PP, Gorusupudi A, Shyam R, Henriksen BS, Nolan JM (2016) Lutein, zeaxanthin, and meso-zeaxanthin: The basic and clinical science underlying carotenoidbased nutritional interventions against ocular disease. Prog. Retin. Eye Res. 50, 34-66.

[12] Bjelakovic G, Nikolova D, Gluud LL, Simonetti RG, Gluud C (2012) Antioxidant supplements for prevention of mortality in healthy participants and patients with various diseases. Cochrane Database Syst. Rev.

[13] Anlasik T, Sies H, Griffiths HR, Mecocci P, Stahl W, Polidori MC (2005) Dietary habits are major determinants of the plasma antioxidant status in healthy elderly subjects. Br. J. Nutr. 94, $639-42$.

[14] Rietman ML, Spijkerman AMW, Wong A, van Steeg H, Bürkle A, Moreno-Villanueva M, Sindlinger T, Franceschi C, Grubeck-Loebenstein B, Bernhardt J, Slagboom PE, Toussaint O, Debacq-Chainiaux F, Sikora E, Gonos ES, Breusing N, Stuetz W, Weber D, Grune T, Basso A, Piacenza F, Malavolta M, Collino S, Jansen EHJM, Verschuren WMM, Dollé MET (2019) Antioxidants linked with physical, cognitive and psychological frailty: Analysis of candidate biomarkers and markers derived from the MARK-AGE study. Mech. Ageing Dev. 177, 135143.

[15] Palczewski G, Amengual J, Hoppel CL, von Lintig J (2014) Evidence for compartmentalization of mammalian carotenoid metabolism. FASEB J. 28, 4457-4469.

[16] Wu L, Guo X, Wang W, Medeiros DM, Clarke SL, Lucas EA, Smith BJ, Lin D (2016) Molecular aspects of $\beta, \beta$-carotene-9', 10'-oxygenase 2 in carotenoid metabolism and diseases. Exp. Biol. Med. (Maywood). 241, 1879-1887. 
[17] Prakash A, Kumar A (2014) Implicating the role of lycopene in restoration of mitochondrial enzymes and BDNF levels in $\beta$-amyloid induced Alzheimer's disease. Eur. J. Pharmacol. 741, $104-11$.

[18] Dias IHK, Polidori MC, Li L, Weber D, Stahl W, Nelles G, Grune T, Griffiths HR (2014) Plasma levels of HDL and carotenoids are lower in dementia patients with vascular comorbidities. $J$. Alzheimers. Dis. 40, 399-408.

[19] Ademowo OS, Dias HKI, Milic I, Devitt A, Moran R, Mulcahy R, Howard AN, Nolan JM, Griffiths HR (2017) Phospholipid oxidation and carotenoid supplementation in Alzheimer's disease patients. Free Radic. Biol. Med. 108, 77-85.

[20] Gimenez-Cassina A, Lim F, Diaz-Nido J (2006) Differentiation of a human neuroblastoma into neuron-like cells increases their susceptibility to transduction by herpesviral vectors. $J$. Neurosci. Res. 84, 755-67.

[21] Moran R, Beatty S, Stack J, O’Halloran AM, Feeney J, Akuffo KO, Peto T, Kenny RA, Nolan JM (2018) The Relationship Between Plasma Concentrations of Lutein and Zeaxanthin with Self-Reported and Actual Prevalence of AMD in an Irish Population-Based Sample. Curr. Eye Res. 43, 383-390.

[22] Wagener S, Völker T, De Spirt S, Ernst H, Stahl W (2012) 3,3'-Dihydroxyisorenieratene and isorenieratene prevent UV-induced DNA damage in human skin fibroblasts. Free Radic. Biol. Med. 53, 457-63.

[23] Talwar D, Ha TK, Cooney J, Brownlee C, O'Reilly DS (1998) A routine method for the simultaneous measurement of retinol, alpha-tocopherol and five carotenoids in human plasma by reverse phase HPLC. Clin. Chim. Acta. 270, 85-100.

[24] Kolamunne RT, Dias IHK, Vernallis AB, Grant MM, Griffiths HR (2013) Nrf2 activation supports cell survival during hypoxia and hypoxia/reoxygenation in cardiomyoblasts; the roles of reactive oxygen and nitrogen species. Redox Biol. 1, 418-26. 
[25] Shrivastava A, Gupta V (2011) Methods for the determination of limit of detection and limit of quantitation of the analytical methods. Chronicles Young Sci. 2, 21.

[26] B. K. Matuszewski *, M. L. Constanzer and, Chavez-Eng CM (2003) Strategies for the Assessment of Matrix Effect in Quantitative Bioanalytical Methods Based on HPLC-MS/MS.

[27] Partani P, Verma SM, Monif T (2016) Development and Validation of an LC-MS-MS Method for Determination of Simvastatin and Simvastatin Acid in Human Plasma: Application to a Pharmacokinetic Study. J. Chromatogr. Sci. 54, 1385-96.

[28] Ferrick DA, Neilson A, Beeson C (2008) Advances in measuring cellular bioenergetics using extracellular flux. Drug Discov. Today 13, 268-274.

[29] Mdaki KS, Larsen TD, Weaver LJ, Baack ML (2016) Age Related Bioenergetics Profiles in Isolated Rat Cardiomyocytes Using Extracellular Flux Analyses. PLoS One 11, e0149002.

[30] Lopert P, Day BJ, Patel M (2012) Thioredoxin reductase deficiency potentiates oxidative stress, mitochondrial dysfunction and cell death in dopaminergic cells. PLoS One 7, e50683.

[31] Bohn T, Bohn, Torsten (2019) Carotenoids and Markers of Oxidative Stress in Human Observational Studies and Intervention Trials: Implications for Chronic Diseases. Antioxidants $8,179$.

[32] Johnson EJ, Maras JE, Rasmussen HM, Tucker KL (2010) Intake of lutein and zeaxanthin differ with age, sex, and ethnicity. J. Am. Diet. Assoc. 110, 1357-62.

[33] Lin MT, Beal MF (2006) Mitochondrial dysfunction and oxidative stress in neurodegenerative diseases. Nature 443, 787-795.

[34] Schon EA, Przedborski S (2011) Mitochondria: The Next (Neurode)Generation. Neuron 70, $1033-1053$.

[35] Koopman WJH, Distelmaier F, Smeitink JA, Willems PH (2012) OXPHOS mutations and neurodegeneration. EMBO J. 32, 9-29. 
[36] Vogl F, Humpolícková J, Amaro M, Koller D, Köfeler H, Zenzmaier E, Hof M, Hermetter A (2016) Role of protein kinase $\mathrm{C} \delta$ in apoptotic signaling of oxidized phospholipids in RAW 264.7 macrophages. Biochim. Biophys. Acta - Mol. Cell Biol. Lipids 1861, 320-330.

[37] Bohn T, Desmarchelier C, Dragsted LO, Nielsen CS, Stahl W, Rühl R, Keijer J, Borel P (2017) Host-related factors explaining interindividual variability of carotenoid bioavailability and tissue concentrations in humans. Mol. Nutr. Food Res. 61, 1600685.

[38] Findlay JA, Hamilton DL, Ashford MLJ (2015) BACE1 activity impairs neuronal glucose oxidation: rescue by beta-hydroxybutyrate and lipoic acid. Front. Cell. Neurosci. 9, 382.

[39] Chiang M-C, Cheng Y-C, Chen S-J, Yen C-H, Huang R-N (2016) Metformin activation of AMPK-dependent pathways is neuroprotective in human neural stem cells against Amyloidbeta-induced mitochondrial dysfunction. Exp. Cell Res. 347, 322-331.

[40] Miura S, Saitoh S-I, Kokubun T, Owada T, Yamauchi H, Machii H, Takeishi Y (2017) Mitochondrial-Targeted Antioxidant Maintains Blood Flow, Mitochondrial Function, and Redox Balance in Old Mice Following Prolonged Limb Ischemia. Int. J. Mol. Sci. 18,.

[41] Widomska J, Zareba M, Subczynski W (2016) Can Xanthophyll-Membrane Interactions Explain Their Selective Presence in the Retina and Brain? Foods 5, 7.

[42] Grudzinski W, Nierzwicki L, Welc R, Reszczynska E, Luchowski R, Czub J, Gruszecki WI (2017) Localization and Orientation of Xanthophylls in a Lipid Bilayer. Sci. Rep. 7, 9619.

[43] Kostecka-Gugała A, Latowski D, Strzałka K (2003) Thermotropic phase behaviour of $\alpha$ dipalmitoylphosphatidylcholine multibilayers is influenced to various extents by carotenoids containing different structural features- evidence from differential scanning calorimetry. Biochim. Biophys. Acta - Biomembr. 1609, 193-202.

[44] Gruszecki WI (1999) Carotenoids in Membranes. In The Photochemistry of Carotenoids Kluwer Academic Publishers, Dordrecht, pp. 363-379.

[45] Lindbergh CA, Lv J, Zhao Y, Mewborn CM, Puente AN, Terry DP, Renzi-Hammond LM, 
Hammond BR, Liu T, Miller LS (2019) The effects of lutein and zeaxanthin on resting state functional connectivity in older Caucasian adults: a randomized controlled trial. Brain Imaging Behav. https://do, 1-14.

[46] Lampl, T., et al., Isolation and functional analysis of mitochondria from cultured cells and mouse tissue. J Vis Exp, 2015(97).

[47] Lapointe, J. and S. Hekimi, Early mitochondrial dysfunction in long-lived Mclk1+/mice. J Biol Chem, 2008. 283(38): p. 26217-27. 